\title{
Predicting segmental substitution errors in aphasic patients with phonological and phonetic encoding impairments
}

\author{
Anna Marczyk and Lorraine Baqué \\ Universitat Autònoma de Barcelona \\ anna.marczyk@uab.es, lorraine.baque@uab.es
}

\begin{abstract}
Submitted: 10/04/2015. Accepted: 17/07/2015. Available on line: 13/06/2016
Citation / Cómo citar este artículo: Anna Marczyk and Lorraine Baqué. Predicting segmental substitution errors in aphasic patients with phonological and phonetic encoding impairments. Loquens, 2(2), e023. doi: http://dx.doi. org/10.3989/loquens.2015.023
\end{abstract}

\begin{abstract}
This paper analyses the factors that predict substitution errors produced by four Broca's and four conduction aphasic subjects, all native speakers of Spanish, in reading and repetition tasks. Errors were elicited using a list of words where type of consonant, lexical stress and phonetic context were controlled for and where variables related to frequency of occurrence (word and syllable) and phonological neighbourhood characteristics were assigned using available online corpora.

675 substitution errors were obtained and preferential tendencies to devoice, occlusivise or spirantise were identified. Logistic regression mixed-effect models were performed on these three types of substitution errors to identify the predictors depending on the aphasic profile.

While our results lent support to the hypothesis of a concomitant phonetic deficit in fluent aphasia, contrary to the classical claim, it also revealed differential patterns in the phonic behaviour of patients regarding the access to mental syllabary or syllabic position effects.

Our results are discussed in relation to the phonetic vs. phonological impairments dimension in aphasia and the seriality/interactivity axis in speech architectures.
\end{abstract}

Keywords: phonetic and phonological impairments; aphasia; substitution errors.

RESUMEN: Estudio de predictores de los errores segmentales de sustitución en pacientes afásicos con un déficit fonético-fonológico. Este estudio se propone identificar los factores que permiten predecir la aparición de errores segmentales de sustitución producidos por pacientes con afasia de Broca y de conducción en tareas de lectura y de repetición. El corpus utilizado para obtener los errores consistía en 240 palabras en las que las consonantes objeto de estudio - oclusivas, fricativas y africadas del español - se encontraban en distintos contextos fonéticos y acentuales. Posteriormente, se atribuyó a las palabras del corpus los valores relativos a la frecuencia léxica y silábica, así como las características relacionadas con la vecindad fonológica, empleando para ello corpus disponibles en línea.

En total, se obtuvieron 675 sustituciones, en las que prevalecen tres tendencias: ensordecimiento de las oclusivas sonoras, refuerzo (oclusivización) de las fricativas y espirantización de las oclusivas. Para identificar los predictores de cualquiera de estos tres tipos de substitución en relación con el perfil clínico de afasia, se efectuó un análisis mediante el modelo mixto de regresión logística.

Los resultados son globalmente congruentes con la hipótesis de un déficit fonético concomitante al déficit fonológico en la afasia de conducción, contrariamente a las predicciones de la hipótesis clásica. Sin embargo, el examen de los errores revela también patrones de tratamiento fónico distintos según el cuadro clínico, en relación con el silabario mental y la influencia de la posición silábica.

Se propone una interpretación de estos resultados en el marco del espectro de déficits fonético-fonológicos en la afasia, así como en relación con la dimensión serialidad vs. interactividad que los modelos de codificación del habla.

Palabras clave: trastornos fonéticos y fonológicos; afasia; errores de sustitución. 


\section{INTRODUCTION}

Speech production models guiding research in the field of acquired speech impairments are anchored in contrasting viewpoints about the nature of language and mechanisms involved in speech production and its impairments. One such viewpoint holds that language is composed of relatively autonomous processing subsystems where each of them is assigned a specific functional role such as lexical or morphological processing. In this account, speech production is conceptualised as a linear top-down process combining retrieval of information stored in the memory and computation processes involving units of encoding specific to a given domain. In architectures based on these assumptions (e.g. Garrett, 1980; Levelt, 1989, 1999), phonological and phonetic encodings are thus regarded as two functionally separate and largely independent components organised hierarchically with phonological encoding giving output for further phonetic programming. Importantly, the word-form encoding proceeds according to the principle of seriality, dominant in this account, which postulates that only one item selected during the phonological encoding can constitute the entry of the phonetic module, where it is further translated into motor commands. A shortcoming of such architectures, with respect to phonetic and phonological processing, consists in the fact that it does not account for the variability which is systematically revealed during the conversion of higher level representations into overt speech.

An opposed view, embraced by connectionist models (e.g. Dell, Chang \& Griffin, 1999; Dell, Juliano \& Govindjee, 1993; Dell, Schwartz, Martin, Saffran \& Gagnon, 1997; Dell \& O'Seaghdha, 1992; Thomas \& McClelland, 2008 ), envisages speech production as a network of elements in interaction and a continuous processing space where gradient phenomena are easily accommodated but where specific functional components are not so easily isolated. In contrast to serial architectures, connectionist models allow information activated at former stages of encoding to influence processing at later levels. An important methodological consequence of such a conceptualization of information flow is that the speech output may contain traces of information partially activated and streamlined from an earlier to later stage, such as phonological characteristics of words similar in form to the target word that the speaker intends to produce. Within the connectionist framework, phonological and phonetic domains are thus conceived of as partly overlapping and inextricably intertwined such that clear-cut boundaries do not exist. However, while these models have generated specific hypotheses concerning phonological encoding, less attention has been devoted to the subsequent and ultimate phonetic stage and the exact mechanisms whereby symbolic phonological representations are transformed into articulatory gestures.

It is within these contrasting frameworks that researchers have tried to elucidate the underlying nature of errors affecting the sound shape of words - substitutions, deletions, insertions and metatheses-commonly referred to in the aphasic bibliography as phonemic paraphasias (see Buckingham, 1992 for a review). Errors perceived as segmental substitutions are among the main symptoms of several acquired neurological disorders including Broca's aphasia, apraxia of speech and conduction aphasia, and the underlying mechanisms that give rise to them are generally situated at one of the processing levels between lexical access and articulation (e.g. Code, 1998; Ziegler, 2002, 2008). However, what mechanism is exactly responsible for these errors remains a matter of debate (e.g. recent studies or reviews by Buchwald \& Miozzo, 2012; Kurowski \& Blumstein, 2016; Laganaro, 2015; Pouplier \& Hardcastle, 2005). The present paper is highly concerned with this question and seeks to contribute to the existing evidence by addressing some of the understudied issues related to the mechanisms responsible for substitution errors in Broca's and conduction aphasia. In the following paragraphs we will situate our research questions within the broad context of studies on phonemic paraphasias and the factors that may constrain them.

In aphasiology, and especially in the field of phonemic paraphasias, one of the main research goals over the past decades has been to establish a threefold correspondence between symptoms, underlying causes and aphasic syndromes (Blumstein, 1973; Blumstein, Cooper, Goodglass, Statlender \& Gottlieb, 1980; Buchwald \& Miozzo, 2012; Buchwald, Rapp \& Stone, 2007; Buckingham, 1986; Buckingham \& Christman, 2008; Canter, Trost \& Burns, 1985; Lecours \& Lhermitte, 1969; Nespoulous, Joanette, Ska, Caplan \& Lecours, 1987; Nespoulous, Lecours \& Joanette, 1983; Tesak \& Code, 2008 among others). This objective was framed with ease within the modular framework of language encoding precisely because of the modularity assumption but also because of the apparent naturalness with which this framework accommodated the double dissociation procedure (but see Plaut, 1995; Shallice, 1988), thus allowing researchers to link selective impairments of a processing component with a particular clinical syndrome. A classical hypothesis in aphasiology oriented by this viewpoint has opposed a phonetic deficit, attributed to Broca's aphasia and apraxia of speech, to a phonological deficit in conduction aphasia (e.g. Alajouanine, Ombredane \& Durand, 1939; Béland \& Valdois, 1989; Lecours \& Lhermitte, 1969; Valdois \& Nespoulous, 1998). Evidence to support or reject this claim came mainly from two kinds of studies, on the one hand perceptual studies that attempted to identify the factors which promote or constrain a given error type (Laganaro \& Alario, 2006; Laganaro \& Zimmermann, 2010; Romani, Olson, Semenza \& Granà, 2002 among others), and on the other hand from instrumental - acoustic and articulatory-studies that sought to discern the source of disruptions on the basis of fine-grained descriptions of errors presenting a similar surface form (e.g. Baqué, Marczyk, Rosas \& Estrada, 2015; Baum, Blumstein, Naeser \& Palumbo, 1990; Baum \& Slatkovsky, 1993; Blumstein et al., 1980; Buckingham \& Yule, 1987; Nespoulous, Baqué, Rosas, Marczyk \& Estrada, 2013; Pouplier \& Hardcastle, 2005; Tuller \& Seider Story, 1988).

While a number of studies reported evidence supporting the classical claim, other studies, in particular instrumental investigations, reported findings that forced re- 
searchers to reconsider the phonetic vs. phonological impairments dichotomy.

One such set of findings concerns the phenomenon reported first by Blumstein et al. (1980) and thereafter termed a subtle phonetic deficit. Subtle phonetic deficit (see Vijayan \& Gandour, 1995 for a review) refers to the presence of phonetic irregularities revealed by acoustic analyses in the output of aphasic patients with, presumably, phonological but not phonetic deficit (i.e., Wernicke and conduction aphasia). The irregularities observed concern abnormal distributions of values for the acoustic parameters of both consonants (see Vijayan \& Gandour, 1995 for references) and vowels (e.g. Baqué, 2015; Ryalls, 1986), such as longer segmental durations, instability of production, narrower vocalic space and a tendency towards more opening in vowels, or overlapping distributions for voiced and voiceless stops VOT values, which are not registered by the listener's perception. These findings challenge the classical explanation in the sense that they seem to suggest either that fluent aphasic subjects (Wernicke, conduction aphasia) exhibit a concomitant phonetic disorder or that the phonetic irregularities observed result from a disruption at a higher processing level and are carried over to speech output thanks to interaction between the domains, against the predictions of the seriality assumption.

Indeed, when reargued from the connectionist perspective, phonetic deviations encountered in the speech of fluent aphasic patients have been hypothesised to reflect traces of the activated but unselected neighbours of the target word (Kurowski \& Blumstein, 2016). When the phoneme belonging to a competitor is activated, the information specifying its subphonemic features is sent down the system and processed further. This parallel processing results in the irregularities captured by acoustic analyses. Similar patterns have been also observed in normal speakers using the tongue-twisters paradigm (Goldrick \& Blumstein, 2006; Pouplier, Marin \& Waltl, 2014).

The connectionist interpretation of observed acoustic patterns raises several interesting questions and suggests promising research avenues. The first of them concerns interaction. Even within connectionist accounts of speech production, the exact scope of interaction is still an unsettled matter. The controversies concern the question whether interaction influences only adjacent or also distant domains - for example, lexical to articulatory or phonological to articulatory processes - or whether it operates exclusively forward or also backward. An assessment through computational simulation of speech architectures ranging along a serial/interactive dimension for their capacity to account for speech errors (Rapp \& Goldrick, 2000) concludes that these are best accounted for by cascading models with the interaction limited to semantic-phonological domains. Thus, on the one hand, the hypothesis that competition at the lexical and phonological levels exerts influence on articulatory processes needs to be substantiated by more research studying involving not only speakers with speech pathology but also healthy. On the other hand, the existence of co-activation at certain levels does not necessarily rule out the serial organization of certain processes occurring at the motor level. Indeed, there is some evidence sup- porting a modular and hierarchical structure of specific aspects of motor control (see Kent, Kent \& Weismer, 2000 for a review). An examination of speech production architectures relative to word-form encoding processes across the seriality/interactivity dimension may thus give further insights into how speech is produced.

Secondly, the notion that phonetic irregularities are interpreted as traces of lexical competitors - usually lexemes differing from the target word by one interphonemic distance - is a matter of hypothesis, which in turn depends on the model that guides the research question. Thus, the traces hypothesis is based on two underlying assumptions, first, that words compete for selection and, second, that competitors are further processed at later stages of encoding in parallel with the target item, and thus influence their phonetic characteristics.

Regarding the first assumption, previous research carried out within the connectionist framework has shown that the structure of the lexicon, including the number of phonological competitors and their respective potential to be selected, that is, their frequency of occurrence, facilitates lexical access and production accuracy in both healthy subjects and aphasic speakers (e.g. Dell \& Gordon, 2003; Goldrick, Folk \& Rapp, 2010; Gordon, 2002; Gordon \& Dell, 2001; Vitevitch, 2002). Since the lexicon is language-specific, and morphological structures in English and Spanish differ on a number of points, more research is needed to test this hypothesis cross-linguistically. Indeed, Vitevitch and Stamer (2006) found no phonological neighbourhood size effect on response times in a picture-naming task in Spanish speakers and attributed this difference to the differing morphological structure of these two languages. To our best knowledge, the effects of neighbourhood characteristics on aphasic paraphasias produced by Spanish speakers have not been yet examined. Moreover, neighbourhood factors may exert an influence on speech encoding beyond frequency effects. Both connectionist and serial models account for frequency of occurrence effects. In serial frameworks, frequency effects are epistemologically related to the processes of information retrieval and are not limited to lexeme frequency but include as well specific hypotheses regarding syllabic frequency (e.g. Cholin, Dell \& Levelt, 2011; Jescheniak \& Levelt, 1994; Levelt \& Wheeldon, 1994).

The second assumption concerns the interaction between the lexical and phonetic processing. Since the competitors, as mentioned above, differ from the target word in one segment, usually at one interphonemic distance, the hypothesis is that the intermediary phonetic realizations of the segment - i.e., neither [s] and nor [z] but something in between (Kurowski \& Blumstein, 2016) - are due to the influence of the competitor. However, it is possible to imagine that the traces may be due to other factors and influences, whether cognitive variables such as memory, general cognitive effort, error awareness and errors monitoring, or phonetic factors such as articulatory tension. While such questions may be difficult to translate into experimental designs, they are theoretically possible and could contribute to a better understanding of the mechanisms involved in speech production. 
This state-of-the-art-summary shows that at present there does not exist a model that can encompass the multiple dimensions of phonemic paraphasias analyses. The present study does not claim to fill this gap but rather is merely intended to contribute to the existing body of evidence, taking as a starting point some of the questions that have been raised by previous studies. Specifically, it seeks to identify the predictors of segmental substitution errors elicited in reading and repetition tasks, which examine speech production accuracy at a post-lexical level. The substitutions we are concerned with involve a change in the perception of voicing or manner of articulation category. Thus, our primary research goal is to explore the relationship between segmental substitution errors and the following:

- Factors related to frequency including word and syllable frequency and neighbourhood size and neighbourhood frequency mean.

- Phonetic and phonological factors including lexical stress, phonetic context, phonological category of the substituted sound and position in the word.

- How the above factors and potential differences in how they influence errors depending on the aphasic profile.

\section{METHOD}

\subsection{Stimuli}

\subsubsection{Criteria for stimuli preparation}

The errors we study here were elicited using a corpus compiled by Baqué et al. (2008). The principal objective of this corpus was to examine errors that affect the word at the level of the segment and to test them for phonetic variables. Thus, the stimuli list consisted of a set of 240 words which contained target consonants $/ \mathrm{p}, \mathrm{t}, \mathrm{k}, \mathrm{b}, \mathrm{d}, \mathrm{g}$, $\mathrm{f}, \mathrm{s}, \theta, \mathrm{x}, \mathrm{u} \mathrm{j} /$ in different phonetic contexts, stress conditions and vowel environments.

The lexical items belonged to different lexical categories, comprising nouns, verbs, adjectives and adverbs and including both inflected and uninflected forms (e.g., gastar, suspira, gatas, etc.) as well as common and proper nouns (e.g., Zamora, trabajo, etc.). The set contained two monosyllabic items (boj, faz), four tetrasyllabic words (practicante, brazalete, dramático, administrar) and one pentasyllabic word (desfavorable). The remaining 233 stimuli were either bisyllabic or trisyllabic.

\subsubsection{Frequency and neighbourhood aspects of the stimuli}

Some of the variables which we sought to assess in the study were not taken into account during the stimuli creation and were attributed to the lexical items of the stimuli lists at a later stage. This includes the factors describing the neighbourhood characteristics of the target item such as neighbourhood density (henceforth PTHN) and neighbourhood frequency mean (henceforth PTHF), as well as its frequency aspects, including word/lexeme frequency, syllabic frequency and phonemic frequency.

PTHN is defined as the number of lexical entries in a given lexicon that result from a deletion, addition or substitution of a segment with regards to the target item (Vitevitch, 1997). Words can belong to either sparse or dense neighbourhoods. For example, a lexical entry cava can have various phonological neighbours including casa, cara, cama, cabo, daba, caza, calla, acaba, cabra, cavar, clava, etc. and is said to belong to a dense neighbourhood, in contrast to a word like flama which has only a few phonological neighbours like llama, flaca, lama or fama and thus is said to belong to a sparse neighbourhood. According to cascading models of speech production, the neighbours of the "correct" lexical item are hypothetically co-activated during encoding. Moreover, the coactivation strength of competitors may vary depending on the frequency of occurrence of each item. It has been hypothesised that not only the target word frequency but also the frequency of its competitors can influence speech production. In particular, it has been argued that the higher the frequency of a given neighbour, the stronger its chances of being selected against the target less-frequent lexical entry, which offers a plausible explanation for why a less frequent word like cava is likely to be replaced by a more frequent lexical item like casa. This effect is measured by PTHF, defined as the average number of occurrences of all the words in the neighbourhood of the target lexical item (Vitevitch, 1997).

For the majority of items in our stimulus list, the values for both neighbourhood variables were obtained from an on-line cross-linguistic database for phonological and orthographic neighbourhood information (CLEARPOND: Marian, Bartolotti, Chabal \& Shook, 2012). This resource used a film and TV series subtitle corpora consisting of $39,935,628$ words to extract neighbourhood characteristics of the contemporary Spanish lexicon (Cuetos, Glez-Nosti, Barbón \& Brysbaert, 2011).

For words that were not found in the database, the corresponding PTHN and PTHF were calculated by the software automatically.

Apart from neighbourhood characteristics, this study is also concerned with determining the effects of lexical item frequency and syllabic frequency. The word frequency values for all but 44 items on our list ( $82 \%$ of the total) were obtained from a database of 81,323 written tokens by Alameda and Cuetos (1995), available online. The obtained values for the stimuli set ranged from 1 to 702 , with a mean value of $47.06\left(S D^{l}=101.40\right)$, the 44 items were coded for this variable as NA.

The syllabic frequency values were obtained from the online resource SYLLABARIUM by Duñabeitia, Cholin,

${ }^{1}$ High values of SD indicate that word and syllable frequencies are highly skewed, as is habitual in natural languages (Baayen, 2001). 
Corral, Perea and Carreiras (2010), based on B-Pal lexicon by Davis and Perea (Davis \& Perea, 2005). The values for this variable in our dataset ranged from 1 to 2701 , with a mean value of $547.84(S D=775.25)$.

Figure 1 represents schematically all the factors taken into account in the error analyses carried out in the present study.

As depicted in the chart, a given phoneme occupies a specific position in a word, it may pertain to either frequent or infrequent syllables, either stressed or unstressed, and may be embedded in a frequent or infrequent word, or a word belonging to a sparse or dense neighbourhood, with competitors characterised by higher individual frequencies or not. To take an example, $/ \mathrm{p} /$ is word-initial in the noun piso 'flat' and verbs pisó '( $\mathrm{s} / \mathrm{he})$ stepped' and parar 'to stop', and can be embedded in either a stressed (/'piso/) or unstressed syllable (/pi'so/, /pa'rar/), one syllable being more frequent $(/ \mathrm{pa} /)$ than another (/pi/), all of them embedded in words characterised by different individual frequencies of occurrence and pertaining to varying phonological neighbourhoods (e.g., 19 phonological neighbours in the case of piso and pisó and 11 in the case of parar).

\subsection{Subjects}

All the aphasic subjects preselected for this study were recruited from the Hospital Universitari de Bellvitge (Barcelona, Spain) according to a set of prespeci-

Figure 1: Variables taken into account for any given phoneme in the substitution error corpus.

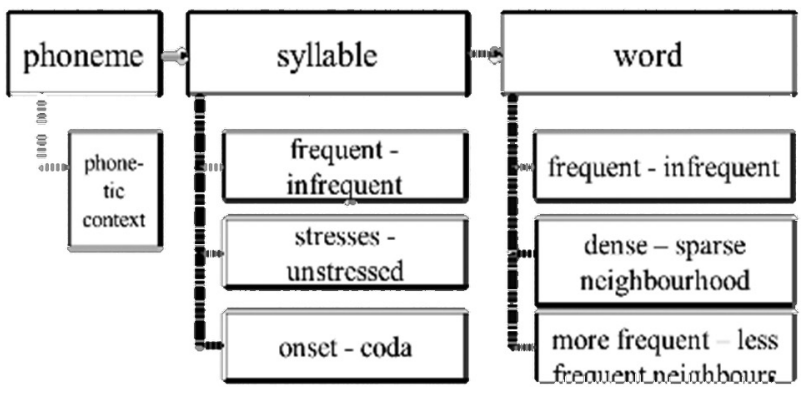

fied inclusion criteria, such as presence of phonemic paraphasias compatible with a Broca's or conduction aphasia profile, intact comprehension and absence of executive function alterations or visual and hearing impairments. All subjects were native speakers of Spanish or bilingual Spanish-Catalan speakers. Out of 10 patients examined, 8 met the above criteria and were further assessed using the MTBA-BCN aphasia battery (Baqué et al., 2006), which confirmed the initial diagnosis of the speech therapist. On the basis of the diagnostic information gathered, the final population was grouped into two clinical categories consisting of four Broca's aphasic subjects and four conduction aphasic subjects. Table 1 provides detailed information about the subjects' characteristics. The exact scores for subjects' performance in aphasia assessment tasks as well as their linguistic description can be found in the Appendix.

\subsection{Procedure}

\subsubsection{Error elicitation}

The lexical items containing target consonants were randomised and placed at the end of short declarative sentences. The list of sentences was printed in 16-point Arial type with 2.0 line spacing, with the target item in boldface (e.g., Esta película es un drama 'This film is a drama'), and presented to the subjects in two experimental conditions, as either a reading or a repetition task. This choice was motivated by the fact that the goal of this study was to elicit errors that arise at the post-lexical level of speech encoding. Subjects were recorded either reading or repeating the stimulus sentences using a Sony ICDCX50 visual voice recorder and a Sony high quality microphone in a soundproof room at the Hospital Universitari de Bellvitge. These tasks were carried out in 4-6 sessions for each subject over a period of 3-4 weeks. The sessions were independent of the speech-language therapy sessions that the subjects were receiving during the study period.

Table 1: Summary of the information regarding the aphasic subjects examined in this study.

\begin{tabular}{|c|c|c|c|c|l|l|}
\hline Subjet & Sex & Age at testing & Aphasia type & $\begin{array}{c}\text { Months post } \\
\text { onset }\end{array}$ & Etiology & Lesion site \\
\hline FNG & M & 68 & Broca & 6 & CVA & frontoparietal, left hemisphere \\
\hline FRG & F & 61 & Broca & 8 & CVA & left middle cerebral artery (MCA) \\
\hline MFB & F & 45 & Broca & 6 & CVA & multiple supratentorial lesions \\
\hline JLLV & M & 40 & Broca & 36 & CVA & left MCA \\
\hline CPB & M & 48 & Conduction & 17 & CVA & subdural parietal hematoma, left hemisphere \\
\hline LFC & M & 57 & Conduction & 8 & Tumor & glioblastoma multiforme, left temporoparietal \\
\hline JMC & M & 50 & Conduction & 7 & CVA & $\begin{array}{l}\text { lenticular region, left MCA, bypassing the } \\
\text { insular and parietal region }\end{array}$ \\
\hline JAOF & M & 57 & Conduction & 1 & CVA & left MCA \\
\hline
\end{tabular}




\subsubsection{Error coding}

Audio recordings of all productions thus obtained were coded according to the subject, task and stimulus number. Every target consonant was identified either as a correct realization of given phoneme (e.g., /k/ in kilo $\rightarrow / \mathrm{k} / \rightarrow$ CORRECT) or as a perceived substitution where the replacement consonant pertained to one of the preselected phoneme categories (e.g., /g/ in gata $\rightarrow / \mathrm{k} / \rightarrow$ ERROR). All the substitutions where the replacing consonant was different from the target set of consonants (e.g., initial /b/ in baba replaced by $/ \mathrm{m} /$ ) as well all the other types of errors were excluded from the present study. Most of the substitutions led to the creation of nonwords (lexical substitutions where the error and the target were semantically related were removed from further analyses). The transcription was carried out by the first author of this paper. In order to validate this classification, two independent native speakers of Spanish were presented with an identification test consisting of randomly chosen items from the data set, including both errors and correct productions, corresponding to $1 \%(N=78)$ of the total number of stimuli, in conditions that closely resembled the original transcription. Cohen's Kappa was used to assess the interrater reliability in SPSS (version 21 for Windows). The inter-judge reliability was $94.2 \%(k=0.033)$ between the author and first rater and complete $(k=1.00)$ between the author and second rater.

\section{RESULTS}

\subsection{Identifying preferential tendencies}

Out of 4824 consonants obtained in both reading and repetition tasks by the aphasic population studied, we obtained 675 productions that could be regarded as substitutions for the target sound. Substitutions represented the most frequent error type and accounted for $14 \%$ of all the production and $60 \%$ of all the segmental errors. This category was followed by segmental deletions (158 errors), distortions (72 errors), contextual substitutions (49 errors) and segmental additions (14 errors). The remaining errors were classified into one of the following categories: lexical substitutions, multiple errors, metathesis errors or "other". The analysis of errors belonging to one of the latter groups is beyond the scope of the present paper.

An initial analysis of substitution errors was carried out to detect preferential tendencies related to the phonological features of voicing and manner of articulation. As illustrated in Figure 2 (all bar graphs were done with $s j$ Plot, Lüdecke, 2015), we observed a strong tendency towards devoicing of voiced stops in both aphasic groups. Devoicing errors accounted for 53\% $(N=245)$ of all substitutions in Broca's group and 48\% $(N=104)$ in the conduction aphasic group. Sonorization errors were rare in both groups, accounting for less than $5 \%$ of all substitutions (19 and 10 errors of this type in the Broca's and conduction groups respectively).
Figure 2: Substitution errors related to the voicing feature by pathology.

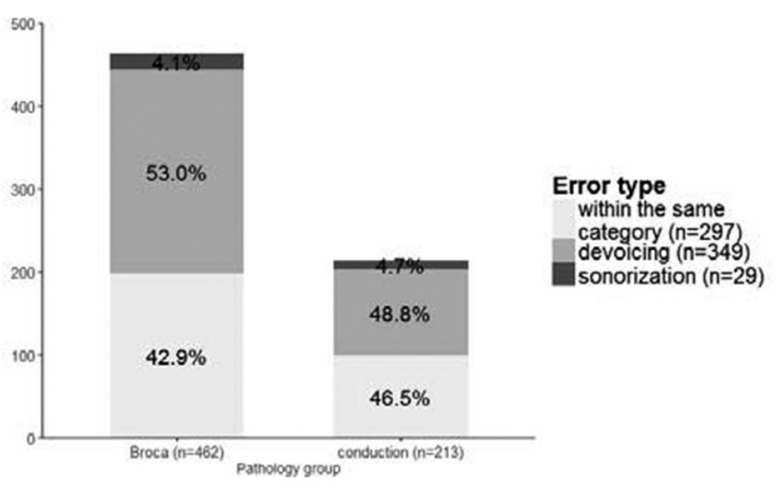

With regard to manner of articulation, two opposite tendencies were identified, a tendency to occlusivise voiceless fricatives $(N=136)$ and a tendency to spirantise stops $(N=89)$. However, Broca's and conduction aphasic groups showed different patterns of errors. In Broca's group there was a dominant tendency to occlusivise voiceless fricatives, accounting for $25.8 \%(N=119)$ of all substitutions, while these errors accounted for $8 \%$ $(N=17)$ of all substitutions in the conduction aphasic group. Conversely, the spirantisation errors accounted for $22.1 \%(N=47)$ of all substitutions in the conduction aphasic group and 9.1\% $(N=42)$ in the Broca's aphasic group. This pattern is depicted in Figure 3.

Finally, all the groups of errors were significantly influenced by phonetic context. Chi square and Fisher tests were performed to examine the relation between phonetic context and different kind of errors. The relation between these variables was significant in all cases and indicated that the devoicing, occlusivisation and spirantisation errors were not equally distributed across all phonetic contexts.

For devoicing errors, as can be seen in Figure 4, we observe more errors in the word-initial position than in any other phonetic context $\left(\chi^{2}(4, N=1068)=64.88, p<.001\right)$.

Figure 3: Substitution errors related to the feature of manner of articulation by pathology: $\mathrm{O}=$ stop, $\mathrm{F}=$ fricative, $\mathrm{A}=$ affricate, where $\mathrm{O}->\mathrm{F}$ stands for spirantisation; $\mathrm{F}->\mathrm{O}$ occlusivisation, etc.

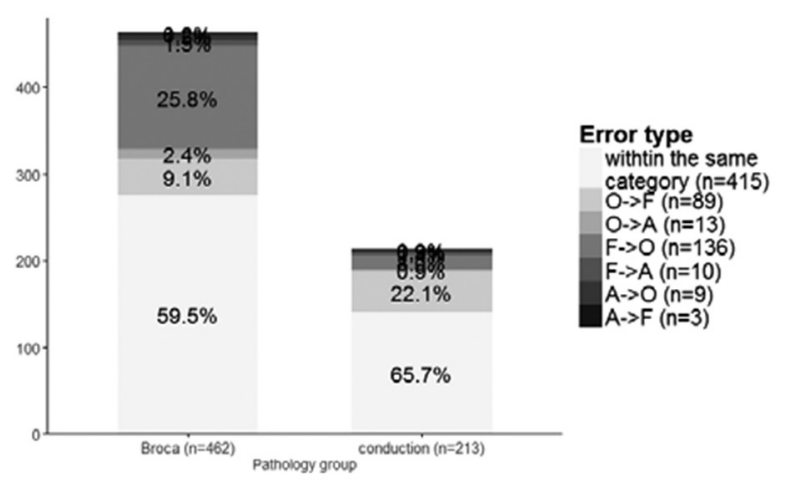


As depicted in Figure 5, occlusivisation errors occurred more frequently in phonetic contexts that correspond to the syllabic onset (word-initial, intersonorant and post-consonantal positions), where word-initial position as well as in post-consonantal position seems to be particularly vulnerable to this type of error $\left(\chi^{2}(4, N=1130)=30.87, p<.001\right)$.

Concerning spirantisation errors, the majority of them were observed in syllabic coda $\left(\chi^{2}(4, N=2518)=84.84\right.$, Fisher $p<.001)$, as illustrated in Figure 6 .

Figure 4: Percentage of devoicing errors in voiced stops according to the phonetic context.

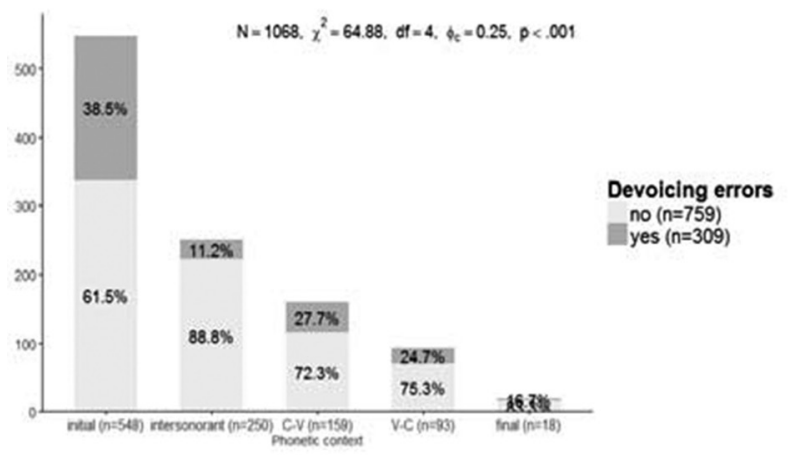

Figure 5: Percentage of occlusivisation errors in voiceless fricatives according to the phonetic context.

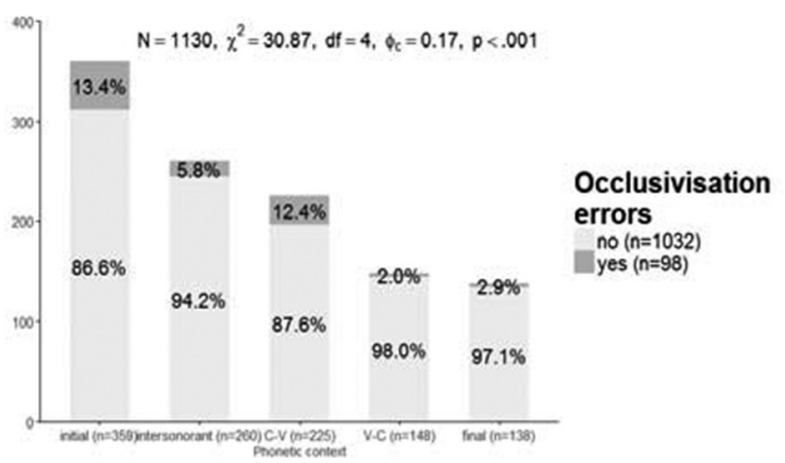

Figure 6: Percentage of spirantisation errors in voiceless fricatives according to the phonetic context.

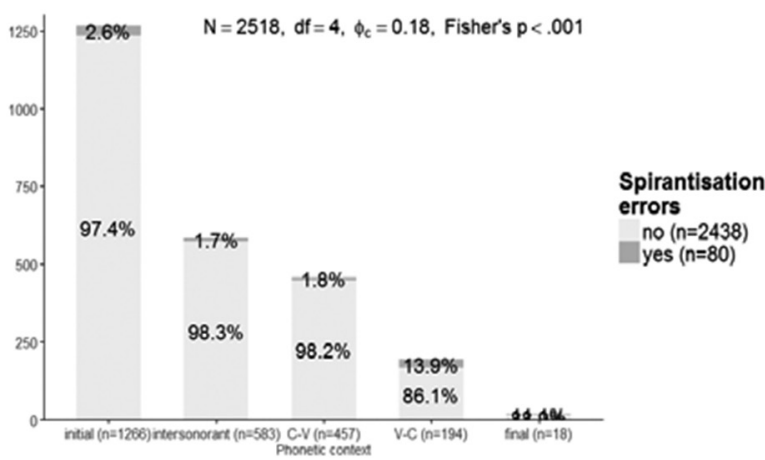

\subsection{Predicting substitution errors}

The regression analyses reported below take as a starting point the results of the descriptive analyses summarised in the previous paragraphs. Substitution error is a broad, non-homogeneous category as suggested by the presence of preferential tendencies. Hence, the following analyses will focus on the three major types of substitution errors revealed by earlier examination: devoicing, occlusivisation and spirantisation errors. A common characteristic of all the error types is their sensitivity to phonetic context and syllabic structure. Clearly, for devoicing errors the wordinitial position is more error-prone in comparison to other phonetic contexts. On the other hand, it is the position in the syllabic structure, onset vs. coda, which seems to trigger different rates of occlusivisation and spirantisation errors. Therefore, for the analyses reported below, we will examine the factors predicting devoicing errors in two phonetic contexts, word-initial and non-initial position, while occlusivisation and spirantisation error categories will be controlled for their position in the syllable, and, when possible, also for the word position.

\subsubsection{Setting the model}

All statistical analyses reported in this paper were performed with the R Studio interface (RStudio Team, 2015) for R statistical software version 3.1.2 for PC (R Development Core Team, 2011). Several mixed-effects logistic regression models were conducted on three binary outcome variables related to the presence of different types of substitution error in different phonetic environments. Subjects and items were entered as random intercepts which captures our data, where both main factors and their interactions are within-subject and within-item. Initial models included the following predictor variables: pathology, lexical stress, task, PTHN, PTHF, lexeme frequency, syllabic frequency, type of consonant and, depending on the outcome variable studied, phonetic context and syllable position. Before entering them into the analysis, all predictors were first checked for collinearity by calculating the variable inflation factor (VIF) for each of them (function available in the package car, Fox \& Weisberg, 2011). All the VIF values tested for each model fell below 2.0, thus confirming the collinearity assumption.

\subsubsection{Rationale for interactions}

Apart from the main effects, we sought to assess, where possible, the effects of interactions between the pathology and the rest of the predictors. The hypothesis that the different underlying error-generating mechanisms are a function of the clinical picture of aphasia would be supported if the interaction between the pathology and the other predictor proved to be statistically 
significant. Our second hypothesis on the nature of the underlying deficit in fluent $v s$. non-fluent aphasic group would be supported if post-hoc pairwise analyses of simple effects went in the expected direction, that is, if (1) no effect of "higher level encoding" variables on the probability of substitution errors was observed in the Broca's aphasia group (2) no effect of "low-level encoding" variables on the outcome variable was observed in the conduction aphasic group.

\subsubsection{Predictors of devoicing errors}

Two analyses were conducted to identify predictors of devoicing errors in initial and non-initial contexts. A devoicing error may occur only on a voiced stop (the phonological contrast of voicing in Spanish is limited to stops), hence, for the analyses reported below we retained all voiced stop consonants $/ \mathrm{b}, \mathrm{d}, \mathrm{g} /$ $(N=520)$. Table 2 shows the confusion matrix for devoicing errors in both groups and across all phonetic contexts.

The first logistic regression model was intended to identify factors predicting devoicing errors produced on word-initial consonants. The following factors were candidates for predicting devoicing errors: lexical stress, PTHN and PTHF, lexeme frequency, syllabic frequency, consonant type, task and pathology, as well as their interactions with pathology.

We identified the following explanatory variables predicting devoicing errors: pathology $\left(\chi^{2}(1)=6.67, p=.010\right.$ ), lexical stress $\left(\chi^{2}(1)=13.48, p=.000\right)$ and consonant type $\left(\chi^{2}(2)=16.92, p=.000\right)$. Neither task, PTHN, PTHF, syl-

Table 2: Confusion matrix for devoicing errors for both Broca's and conduction aphasic subjects.

\begin{tabular}{|c|r|r|r|c|c|c|c|}
\hline \multirow{2}{*}{$\begin{array}{c}\text { Target } \\
\text { consonant }\end{array}$} & \multicolumn{7}{|c|}{ Perceived as: } \\
\cline { 2 - 8 } & \multicolumn{1}{|c|}{$/ \mathbf{p}$} & \multicolumn{1}{|c|}{$/ \mathbf{r} / \mathbf{k} /$} & $/ \mathbf{f} /$ & $/ \mathbf{s}$ & $/ \boldsymbol{\theta} /$ & $/ \mathbf{x} /$ \\
\hline$/ \mathrm{b} /$ & 87 & 2 & 4 & 7 & 1 & 0 & 0 \\
\hline$/ \mathrm{d} /$ & 1 & 33 & 6 & 0 & 2 & 5 & 1 \\
\hline$/ \mathrm{g} /$ & 9 & 4 & 113 & 5 & 2 & 1 & 23 \\
\hline
\end{tabular}

labic frequency, lexeme frequency, nor any interaction between the pathology and other predictors reached the significance level.

The results obtained with the lsmeans function show that the odds ratio of a devoicing error in the word-initial context is 18.66 times lower for conduction aphasia in comparison to Broca's group. Moreover, it is 2.45 times lower $(\mathrm{p}=.000)$ for consonants in stressed syllables vs. unstressed ones (the probability of observing a devoicing errors being $43 \%$ and $24 \%$ in unstressed and stressed syllables respectively). Finally, the stops /b/ and $/ \mathrm{g} /$ are more sensitive to devoicing than $/ \mathrm{d} /$, the respective probabilities of error for each of these consonants being $34 \%, 48 \%$ and $18 \%$. The results of the final model are listed in Table 3.

Secondly, the logistic regression model for devoicing errors in non-initial contexts, including the same set of predictors as above, showed an effect of PTHN on the probability of observing a devoicing error, independently of the pathology group $\left(\chi^{2}(1)=4.84, p=.028\right)$. The result indicates that PTHN has a facilitating effect on accuracy. In other words, the probability of a devoicing error is 1.6 times lower in words pertaining to denser neighbourhoods vs. sparse neighbourhoods in both groups. The likelihood of observing a devoicing error is also influenced by the type of consonant $\left(\chi^{2}(2)=15.13, p=.000\right)$. Analyses revealed that the probabilities of observing a devoicing error are $11 \%, 5 \%$ and $19 \%$ for $/ \mathrm{b} /, / \mathrm{d} /$ and $/ \mathrm{g} /$ respectively. The difference between the error probabilities of $/ \mathrm{d} /$ and $/ \mathrm{g} /$ is statistically significant $(\mathrm{p}=.000)$, while other contrasts do not reach the alpha level set at 0.05 . Moreover, we observe a significant interaction between pathology and syllabic frequency $\left(\chi^{2}(1)=7.57\right.$, $p=.006)$, while syllabic frequency and pathology as main effects did not reach the significance threshold. The examination of this interaction reveals a different pattern for the Broca's and conduction aphasic group. In the Broca's aphasic group the odds ratio of observing a devoicing error are 1.18 times higher for frequent syllables, while in the conduction aphasic group the odds ratio of observing such an error is 3.61 times lower the higher the syllabic frequency. This difference is statistically significant $(p=.006)$. The results of the final model are detailed in Table 4.

Table 3: Summary of the final mixed logistic regression model predicting the devoicing errors in word-initial stops. Predictors (reference category is given in italics): Pathology: Broca, conduction; Lexical stress: unstressed syllable, stressed syllable; Consonant type: /b/,/d/,/g/.

\begin{tabular}{|l|c|c|c|c|c|}
\hline \multicolumn{1}{|c|}{ Predictor } & $\boldsymbol{b}$ & $\mathbf{S E}$ & $\boldsymbol{z}$ value & $(\mathbf{d f}) \boldsymbol{\chi}^{\mathbf{2}}$ & $\boldsymbol{p}$-values* \\
\hline Pathology & -2.93 & 1.13 & -2.58 & $(1)=6.67$ & 0.010 \\
\hline Lexical stress & -0.91 & 0.25 & -3.67 & $(1)=13.48$ & 0.000 \\
\hline Consonant type & & & & $(2)=16.92$ & 0.000 \\
$/ \mathrm{d} /$ & -0.83 & 0.36 & -2.39 & & \\
$/ \mathrm{g} /$ & 0.58 & 0.27 & 2.18 & & \\
\hline
\end{tabular}

*(Type II Wald Chi-square tests). 
Table 4: Summary of the final mixed logistic regression model predicting the devoicing errors in non-initial stops. Predictors (reference category is given in italics): Pathology: Broca, conduction; PTHN: numerical; Consonant type: /b/,/d/,/g/; Syllabic frequency: numerical.

\begin{tabular}{|l|c|c|c|c|c|}
\hline \multicolumn{1}{|c|}{ Predictor } & $\boldsymbol{b}$ & $\mathbf{S E}$ & $\boldsymbol{z}$ value & $(\mathbf{d f}) \boldsymbol{\chi}^{\mathbf{2}}$ & $\boldsymbol{p}$-value** \\
\hline Pathology & -1.18 & 0.84 & -1.41 & $(1)=0.64$ & NS \\
\hline PTHN & -0.47 & 0.21 & -2.27 & $(1)=5.17$ & 0.023 \\
\hline Consonant type & & & & $(2)=15.13$ & 0.000 \\
$/ \mathrm{d} /$ & -0.97 & 0.45 & -2.14 & & \\
$/ \mathrm{g} /$ & 0.60 & 0.43 & 1.38 & & \\
\hline Syllabic frequency & -0.93 & 0.24 & -3.83 & $(1)=14.67$ & NS \\
\hline $\begin{array}{l}\text { Pathology* } \\
\text { syllabic frequency }\end{array}$ & -1.45 & 0.53 & -2.75 & $(1)=7.57$ & 0.006 \\
\hline
\end{tabular}

*(Type II Wald Chi-square tests).

\subsubsection{Predictors of occlusivisation errors}

In order to analyse occlusivisation errors we selected all the voiceless fricative of Spanish. We reported above that the rate of occlusivisation errors was significantly higher in the Broca's aphasic group than in the conduction aphasic group and moreover, that such errors occurred almost exclusively in the syllabic onsets. Hence, for the analyses reported below we retained all the fricatives produced by the Broca's group in any of the three phonetic contexts - word-initial, intersonorant and post-consonantal-corresponding always to the syllabic onset. The confusion matrix for occlusivisation errors in the Broca's group in presented in Table 5.

The following predictors, which satisfied the non-collinearity requirement, were entered in the model: task, neighbourhood frequency mean, word frequency, syllabic frequency, consonant type (/f/, /s/, / / /, /x/), phonetic context (only syllabic onset in the initial, intersonorant and post-consonantal position) and lexical stress (stressed and unstressed syllable).

The PTHN variable was removed from for the predictor candidates list since its VIF factor exceeded the threshold value 2.0.

The analyses of occlusivisation errors in syllabic onset positions in the Broca's group identified the effect of consonant type $\left(\chi^{2}(3)=19.76, p=.000\right)$ and the effect of phonetic context $\left(\chi^{2}(2)=8.18, p=.017\right)$. Lexical stress did not predict the occlusivisation error at the significance

Table 5: Confusion matrix for occlusivisation errors in Broca's aphasic group.

\begin{tabular}{|c|c|c|c|}
\hline \multirow{2}{*}{$\begin{array}{c}\text { Target } \\
\text { consonant }\end{array}$} & \multicolumn{3}{|c|}{ Perceived as: } \\
\cline { 2 - 4 } & $/ \mathbf{p} /$ & $/ \mathbf{t} /$ & $/ \mathbf{k} /$ \\
\hline$/ \mathrm{f} /$ & 28 & 3 & 5 \\
\hline$/ \mathrm{s} /$ & 0 & 2 & 1 \\
\hline$/ \theta /$ & 1 & 12 & 3 \\
\hline$/ \mathrm{x} /$ & 0 & 0 & 29 \\
\hline
\end{tabular}

level set at 0.05 , however it approached this threshold $\left(\chi^{2}(1)=3.69, p=.055\right)$.

Results indicate the lowest probability of occlusivisation error for alveolar /s/ (3\%) and the highest for velar fricative $/ \mathrm{x} /(28 \%)$, followed by labiodental fricative /f/ $(17 \%)$, the odds ratio for $/ \mathrm{f} /$ with respect to $/ \mathrm{s} /$ is 7.18 times higher $(\mathrm{p}=.004)$ while the odds ratio for $/ \mathrm{s} /$ with respect to $/ \mathrm{x} /$ is 13.02 lower $(p=.001)$. All the other contrasts between consonants groups did not reach the significance level.

Finally, the probability of observing an error of this type is the highest in the word-initial position (17\%), this context being followed by the post-consonantal position $(15 \%)$ and it is the lowest in the intersonorant position $(6 \%)$. The odds ratio increases 3.10 times for the word-initial position with respect to the intersonorant one $(p=.017)$, and it decreases 2.29 times for the intersonorant with respect to the post-consonantal position $(\mathrm{p}=.048)$.

Furthermore, the test revealed that the probability of occlusivisation errors increases (the odds ratio is 37.31 times higher, $\mathrm{p}=.055$ ) for fricatives in stressed syllables than in unstressed ones (the probability of errors being $9 \%$ and $15 \%$ in unstressed and stressed syllable respectively), although, as mentioned, this effect failed to reach the alpha level set at 0.05 .

The results of the analyses are listed in Table 6.

\subsubsection{Predictors of spirantisation errors}

Spirantisation errors were observed in both the Broca's and the conduction aphasic group. Table 7 presents the confusion matrix for this type of error, in both groups and across all phonetic contexts.

However, as can be seen from the data in Table 8, the distribution of spirantisation errors in onset and coda positions in the syllabic structure is highly influenced by the aphasic profile. Indeed, while in the conduction aphasic group we observe more errors in the coda position as compared to the syllabic onset, in the Broca's group there are almost no errors in coda and syllabic onset is much more error-prone. 
Table 6: Summary of the final mixed logistic regression model predicting occlusivisation errors in syllabic onsets fricatives produced by Broca's aphasic subjects. Predictors (reference category is given in italics): Lexical stress: unstressed syllable, stressed syllable; Phonetic context: wordinitial, intersonorant, post-consonantal; Consonant type: /f/, /s/, / / //, /x/.

\begin{tabular}{|l|c|c|c|c|c|}
\hline \multicolumn{1}{|c|}{ Predictor } & $\boldsymbol{b}$ & $\mathbf{S E}$ & $\boldsymbol{z}$ value & $(\mathbf{d f}) \boldsymbol{\chi}^{\mathbf{2}}$ & $\boldsymbol{p}$-values* \\
\hline Lexical stress & 0.57 & 0.30 & 1.92 & $(1)=3.69$ & 0.055 \\
\hline Phonetic context & & & & $(2)=8.18$ & 0.017 \\
$\quad$ intersonorant & -1.13 & 0.41 & -2.74 & & \\
post-consonantal & -1.13 & 0.36 & -0.35 & & \\
\hline Consonant type & & & & $(3)=19.75$ & 0.000 \\
/s/ & -1.97 & 0.58 & -3.37 & & \\
/ $\theta /$ & -0.48 & 0.40 & -1.20 & & \\
/x/ & 0.59 & 0.38 & 1.54 & & \\
\hline
\end{tabular}

*(Type II Wald Chi-square tests).

Table 7: Confusion matrix for spirantisation errors in both aphasic groups and across all contexts.

\begin{tabular}{|c|c|c|c|c|}
\hline \multirow{2}{*}{$\begin{array}{c}\text { Target } \\
\text { consonant }\end{array}$} & \multicolumn{5}{|c|}{ Perceived as: } \\
\cline { 2 - 5 } & $/ \mathbf{f} /$ & $/ \mathbf{s} /$ & $/ \boldsymbol{\theta} /$ & $/ \mathbf{x} /$ \\
\hline$/ \mathrm{p} /$ & 28 & 3 & 5 & 0 \\
\hline$/ \mathrm{t} /$ & 0 & 2 & 1 & 5 \\
\hline$/ \mathrm{k} /$ & 1 & 12 & 3 & 4 \\
\hline$/ \mathrm{b} /$ & 0 & 0 & 29 & 0 \\
\hline
\end{tabular}

Table 8: Distribution of spirantisation errors depending on syllable position.

\begin{tabular}{|c|c|c|}
\hline \multicolumn{3}{|c|}{ Broca conduction } \\
\hline Onset & 36 & 16 \\
\hline Coda & 2 & 26 \\
\hline
\end{tabular}

Therefore, we collapsed the spirantisation errors across all the phonetic contexts, and conducted one logistic regression mixed model where we entered the position in the syllable structure (onset and coda) as predictor along with other factors including: task, phonological neighbourhood size, neighbourhood frequency mean, syllabic frequency, word frequency, stress, consonant type and pathology. Since we hypothesise that the pathology may affect how these factors influence the likelihood of the appearance of spirantisation errors, we included interactions in the model.

The results of the model confirm that the syllable position predicts the errors differently depending on the aphasic profile $\left(\chi^{2}(1)=21.23, p=.000\right)$. The probability of such errors happening in the syllabic coda in the conduction aphasic group is $13 \%$, against $2 \%$ in the Broca's group in the same position. For the syllabic coda, the odds ratio decreases 12.85 times for Broca's group in comparison with conduction aphasic group $(\mathrm{p}=.000)$. The difference between these two groups with respect to the syllabic onset is not significant (the probability of a spirantisation error being $2 \%$ and $0.7 \%$ for Broca's and conduction aphasic group respectively). Furthermore, we observe an effect of syllabic frequency $\left(\chi^{2}(1)=5.23\right.$, $p=.022)$, which is independent of the aphasic profile. The probability of spirantisation errors decreases for more frequent syllables, the odds ratio decreases 1.59 times for every unit of increase in syllabic frequency. Finally, the spirantisation errors were significantly predicted by consonant type $\left(\chi^{2}(5)=21.48, p=.001\right)$. The velar stop /g/ triggers a spirantisation error with the highest probability in comparison to all other voiced or voiceless stops (this probability being of $6 \%$ for $/ \mathrm{g} /$, against the probabilities lower than $3 \%$ for all the other stops). With respect to $/ \mathrm{g} /$, the odds ratio decreases 3.52 times for voiceless bilabial $/ \mathrm{p} /(\mathrm{p}=.007), 3.51$ for voiceless velar $/ \mathrm{k} /(\mathrm{p}=.012)$ and 4.30 times for voiced dental $/ \mathrm{d} /$ $(p=.017)$, the least vulnerable for this type of error. Other contrasts are not significant. The results are summarised in Table 9.

\subsubsection{Summary of results}

The goal of the analyses reported in the preceding paragraphs was to identify factors predicting three different kinds of substitution errors - devoicing, occlusivisation and spirantisation-observed in the aphasic speech output. We will summarize below the main findings according to the predictor candidate across all the tests.

First, the analyses reveal a strong effect of pathology across different contexts and error types. The clinical picture of aphasia seems to exert a quantitative and-albeit to a lesser extent - qualitative influence on the likelihood of different categories of substitution errors. This is evident in the higher number of both devoicing and occlusivisation 
Table 9: Summary of the final mixed logistic regression model predicting spirantisation errors. Predictors (reference category is given in italics): Pathology: Broca, conduction; Syllabic frequency: numerical; Syllabic position: coda, onset; Consonant type: /p/, /t/, /k/, /b/, /d/, /g/.

\begin{tabular}{|l|c|c|c|c|c|}
\hline \multicolumn{1}{|c|}{ Predictor } & $\boldsymbol{b}$ & $\mathbf{S E}$ & $\boldsymbol{z}$ value & $(\mathbf{d f}) \boldsymbol{\chi}^{2}$ & $\boldsymbol{p}$-values* \\
\hline Pathology & 2.55 & 0.94 & 2.72 & $(1)=0.86$ & NS \\
\hline Syllabic frequency & -0.46 & 0.20 & -2.28 & $(1)=5.23$ & 0.022 \\
\hline Syllabic position & 0.60 & 0.74 & 0.80 & $(1)=44.33$ & 0.000 \\
\hline Consonant type & & & & $(5)=21.48$ & 0.001 \\
/t/ & 42 & 0.50 & 0.85 & & \\
/k/ & 0 & 0.43 & 0.01 & & \\
/b/ & 0.18 & 0.48 & 0.38 & & \\
/d/ & -0.20 & 0.49 & -0.40 & & \\
/g/ & 1.26 & 0.36 & 3.46 & & \\
\hline Pathology* & -3.73 & 0.81 & -4.06 & $(1)=21.23$ & 0.000 \\
syllabic position & & & & & \\
\hline
\end{tabular}

*(Type II Wald Chi-square tests).

errors in the Broca's aphasic group as compared to the conduction aphasic group, with occlusivisation errors practically absent in the latter. Of the three syllabic contexts examined, the word-initial position was the most susceptible to errors for both groups and both types of errors. This finding is consistent with evidence reported in previous studies showing that non-fluent aphasic subjects have particular difficulty with the initiation of speech (e.g. Code, 1998; Kent \& Rosenbek, 1983).

Second, our results show that consonant type has a consistent effect on the likelihood of substitution errors across all the tests except for spirantisation errors. Overall, the analyses suggest that the coronal fricative /s/ and stop /d/ are the least vulnerable to errors of any kind, whereas velar fricative $/ \mathrm{x} /$ and stop $/ \mathrm{g} /$ trigger more errors, with these errors being occlusivisation in the case of $/ \mathrm{x} /$ and spirantisation in the case of $/ \mathrm{g} /$. This result is independent of the aphasic profile, as suggested by the absence of significant interactions between consonant type and pathology group. Another frequent error type was occlusivisation of syllable onset /f/ $(/ \mathrm{f} / \rightarrow / \mathrm{p} /)$, observed in the Broca's group speech output. It should be noted that /f/ is the only possible fricative constituent of a complex syllabic onset in Spanish (as in frasco 'jar').

Third, a contrasting pattern of results was observed for lexical stress. Our results show that lexical stress has a facilitating effect for word-initial devoicing errors, more frequent in unstressed syllables in comparison with stressed ones, independently of the aphasic profile (a similar effect was found for omission errors by Nickels \& Howard, 1999). On the other hand, for the analyses performed on occlusivisation errors in the Broca's aphasic group, stressed syllables were found to trigger more errors than unstressed ones. This finding may suggest that occlusivisation errors in this clinical group may originate from a lack of an appropriate level of articulatory tension, especially when the articulatory tension is reinforced by phonetic factors including not only the lexical stress but also syllabic position and phonetic context. The effect of stress was not observed for spirantisation errors, a process involving articulatory weakening.

Regarding phonological neighbourhood effects, the neighbourhood size measured in the number of phonologically similar words was found to be facilitating for accuracy of production in the case of devoicing nonword-initial errors. This effect was not influenced by the aphasic profile. This result is consistent with findings for aphasic speech in English (Gordon, 2002 for lexical access; Kurowski \& Blumstein, 2016 for errors related to voicing). To our best knowledge there is no study for Spanish on the effect of this variable on aphasic production, and while there are studies on its effect on lexical retrieval, we are not aware of any work on the influence of neighbourhood size on post-lexical encoding. No effect of lexeme frequency or PTHF was found in any of the analyses reported in this study. Lack of PTHF effect is consistent with previous research on aphasic speech (e.g. Gordon, 2002). As for the word frequency, this effect may be overshadowed by a more robust neighbourhood size effect or factors intervening at phonological and phonetic encoding such as consonant type, syllabic position or lexical stress.

Finally, we observed two kinds of interactions with aphasic profile, one involving syllabic frequency and another syllabic position. In the case of non-initial devoicing errors, the conduction aphasic group proved more sensitive to syllabic frequency than the Broca's group, in the sense that conduction aphasic patients produced significantly fewer errors in frequent syllables as opposed to infrequent. These results reinforce the hypothesis that phonetic encoding follows a dual route, where one of the routes consists in accessing ready-made motor programs for frequent syllables stored in a syllabary at the interface between phonological and phonetic encoding, and the 
second and indirect route involves on-line assembling motor programs for infrequent or new syllables (Levelt \& Wheeldon, 1994). Moreover, the hypothesis proposed by Varley and Whiteside $(1998,2001)$, which posits a loss of access to the mental syllabary in apraxia of speech (Broca's aphasia), seems congruent with our findings for Spanish-speaking aphasic subjects. Interestingly, however, this result suggests that conduction aphasic patients have difficulty with a strictly phonetic task, namely, composing motor programmes for articulation on-line.

With respect to the syllabic position effect, we found that syllable onsets were overall more sensitive to errors in the Broca's group. The difference between groups concerned spirantisation errors, where we observed more errors in the coda position in conduction aphasia and in the onset position in Broca's aphasia. While the pattern of errors in the conduction aphasic group can be explained by articulatory weakening in the syllabic coda, consistent with the phonological processes in normal speech, the finding for the Broca's group calls for an entirely different interpretation, which again may be related to inappropriate articulatory tension.

\section{DISCUSSION}

The evidence reported in this paper can be discussed in relation to two major issues disclosed in the introduction. The first of them concerns the classical dichotomy of phonetic vs. phonological errors in aphasic speech and its relation to the clinical dichotomy of Broca's and conduction aphasia. The second concerns the seriality/interactivity axis. The present investigation contributes to these debates by providing evidence from Spanish-speaking aphasic subjects.

Three main conclusions can be drawn from the analyses reported above. First, processing at the phonetic and phonological levels of encoding, and consequently any impairment of these processes, is influenced by higher stage processes, such as competition between phonological neighbours, and this influence is similaralthough possibly robust to varying degrees - in Broca's and conduction aphasia. More specifically, the neighbourhood size plays a facilitating role and promotes accuracy in aphasic speech in patients with a phonological and phonetic level deficit. This result is consistent with that reported by Kurowski and Blumstein (2016), a study that asks very different research questions and is also very different methodologically. Kurowski and Blumstein (2016) examine the acoustic characteristics of devoicing and voicing errors of fricative consonants /s/ and /z/ in English, while ours is a perceptual study aimed at identifying the predictors of productions perceived as segmental substitutions. Thus, while our study indicates that interactions between lexical and phonetic level exist, it cannot confirm or reject the 'traces hypothesis'. A crossed instrumental and perceptual as well as cross-linguistic study on these effects could provide further insights into the interaction between lexical and post-lexical encoding levels, including the nature of 'acoustic traces'.

The second conclusion is related to the existence of common effects, either promoting or constraining errors, which are independent of aphasic profiles. Our findings lend support to the hypothesis, embraced by connectionists, that errors are sensitive to some universal aspects of speech production (see the classical study by Blumstein, 1973). These commonalities play themselves out in the existence of preferential tendencies and variable effects in both aphasic groups and suggest that aphasic syndromes may be better described with the notion of 'spectrum of disorders' rather than clear-cut categories.

Finally, our third conclusion tones down second one. Though our findings indicate that not only disfluent but also fluent aphasic patients exhibit a phonetic disorder, they also suggest that these phonetic deficits are not entirely similar in the two groups. Particular factors, such as difficulty in initiating speech or control of articulatory tension, may reinforce the phonetic impairment in Broca's aphasia but play no role in conduction aphasia. Finally, different factors may promote accuracy depending on the clinical profile. Indeed, our results show that high frequency of syllables may facilitate correct production of consonants in conduction aphasia but not in Broca's aphasia.

\section{REFERENCES}

Alajouanine, T., Ombredane, A., \& Durand, M. (1939). Le syndrome de désintégration phonétique dans l'aphasie. Paris: Masson.

Alameda, J., \& Cuetos, F. (1995). Diccionario de frecuencias de las unidades lingüisticas del castellano. Oviedo: Servicio de Publicaciones de la Universidad de Oviedo.

Baayen, H. R. (2001). Word frequency distributions. Dordrecht: Kluwer Academic Publishers. http://dx.doi.org/10.1007/978-94-010-0844-0.

Baqué, L. (2015). Velocidad de articulación y estructuración del espacio vocálico en función del acento en la afasia: un estudio preliminar. In A. Cabedo Nebot (Ed.), Normas. Perspectivas actuales en el análisis fónico del habla: tradición y avances en la fonética experimental (Vol. 7, pp. 297-308). Retrieved from http://ampercan.webs.ull.es/sites/default/files/Libro_Fonetica 2015.pdf.

Baqué, L., Estrada, M., Nespoulous, J.-L., Le Besnerais, M., Rosas, A., \& Marczyk, A. (2006). Protocole Initial du projet Cognifon. Barcelona.

Baqué, L., Estrada, M., Nespoulous, J.-L., Le Besnerais, M., Rosas, A., \& Marczyk, A. (2008). Corpus léxico del proyecto COGNIFON. Barcelona [Unpublished technical document].

Baqué, L., Marczyk, A., Rosas, A., \& Estrada, M. (2015). Disability, repair strategies and communicative effectiveness at the phonic level: Evidence from a multiple-case study. In C. Astésano \& M. Jucla (Eds.), Neuropsycholinguistic perspectives on language cognition (pp. 144-165). Cambridge: Routledge Taylor \& Francis.

Baum, S. R., Blumstein, S. E., Naeser, M. A., \& Palumbo, C. L. (1990). Temporal dimensions of consonant and vowel production: An acoustic and CT scan analysis of aphasic speech. Brain and Language, 39(1), 33-56. http://dx.doi. org/10.1016/0093-934X(90)90003-Y.

Baum, S. R., \& Slatkovsky, K. (1993). Phonemic false evaluation?: Preliminary data from a conduction aphasia patient. Clinical Linguistics \& Phonetics, 7(3), 207-218. http://dx.doi. org/10.3109/02699209308985558. 
Béland, R., \& Valdois, S. (1989). Les perturbations phonétiques et phonémiques: nouvelles perspectives. Langages, 24e Année, 96, 44-63. http://dx.doi.org/10.3406/lgge.1989.1558.

Blumstein, S. E. (1973). A phonological investigation of aphasic speech. The Hague: Mouton.

Blumstein, S. E., Cooper, W. E., Goodglass, H., Statlender, S., \& Gottlieb, J. (1980). Production deficits in aphasia: A voice-onset time analysis. Brain and Language, 9(2), 153-170. http:// dx.doi.org/10.1016/0093-934X(80)90137-6.

Buchwald, A., \& Miozzo, M. (2012). Phonological and motor errors in individuals with acquired impairment. Journal of Speech, Language, and Hearing Research, 55(5), S1573-S1586. http:/ dx.doi.org/10.1044/1092-4388(2012/11-0200).

Buchwald, A., Rapp, B., \& Stone, M. (2007). Insertion of discrete phonological units: An ultrasound investigation of aphasic speech. Language and Cognitive Processes, 22(6), 910-948. http://dx.doi.org/10.1080/01690960701273532.

Buckingham, H. W. (1986). The scan-copier mechanism and the positional level of language production: Evidence from phonemic paraphasia. Cognitive Science, 10, 195-217. http://dx.doi. org/10.1207/s15516709 $\operatorname{cog} 10024$

Buckingham, H. W. (1992). The mechanisms of phonemic paraphasia. Clinical Linguistics \& Phonetics, 6(1-2), 41-63. http:// dx.doi.org/10.3109/02699209208985518.

Buckingham, H. W., \& Christman, S. (2008). Disorders of phonetics and phonology. In B. Stemmer \& H. A. Whitaker (Eds.), Handbook of the Neuroscience of Language (pp. 127-136). London: Academic Press Elsevier. http://dx.doi.org/10.1016/ B978-0-08-045352-1.00012-4

Buckingham, H. W., \& Yule, G. (1987). Phonemic false evaluation: Theoretical and clinical aspects. Clinical Linguistics \& Phonetics, 1(2), 113-125. http://dx.doi.org/10.3109/02699208708985007.

Canter, G. J., Trost, J. E., \& Burns, M. S. (1985). Contrasting speech patterns in apraxia of speech and phonemic paraphasia. Brain and Language, 24(2), 204-222. http://dx.doi. org/10.1016/0093-934X(85)90131-2.

Cholin, J., Dell, G., \& Levelt, W. (2011). Planning and articulation in incremental word production: Syllable-frequency effects in English. Journal of Experimental Psychology: Learning, Memory, and Cognition, 37(1), 109-22. http://dx.doi.org/10.1037/ $\mathrm{a} 0021322$.

Code, C. (1998). Models, theories and heuristics in apraxia of speech. Clinical Linguistics and Phonetics, 12(1), 47-65. http:// dx.doi.org/10.3109/02699209808985212.

Cuetos, F., Glez-Nosti, M., Barbón, A., \& Brysbaert, M. (2011). SUBTLEX-ESP: Spanish word frequencies based on film subtitles. Psicológica, 32, 133-143.

Davis, C. J., \& Perea, M. (2005). BuscaPalabras: A program for deriving orthographic and phonological neighborhood statistics and other psycholinguistic indices in Spanish. Behavior Research Methods, 37, 665-671. http://dx.doi.org/10.3758/ BF03192738.

Dell, G., Chang, F., \& Griffin, Z. M. (1999). Connectionist models of language production: Lexical access and grammatical encoding. Cognitive Science, 23, 517-542. http://dx.doi.org/10.1207/ s15516709 $\operatorname{cog} 2304$. 6 .

Dell, G., \& Gordon, J. K. (2003). Neighbors in the lexicon: Friends or foes? In N. O. Schiller \& A. S. Meyer (Eds.), Phonetics and phonology in language comprehension and production: Differences and similarities (pp. 9-38). New York: Mouton de Gruyter. http://dx.doi.org/10.1515/9783110895094.9.

Dell, G., Juliano, C., \& Govindjee, A. (1993). Structure and content in language production: A theory of frame constraints in phonological speech errors. Cognitive Science, 17(2), 149-195. http:// dx.doi.org/10.1207/s15516709 $\operatorname{cog} 1702$ 1.

Dell, G., \& O'Seaghdha, P. G. (1992). Stages of lexical access in language production. Cognition, 42, 287-314. http://dx.doi. org/10.1016/0010-0277(92)90046-K.

Dell, G., Schwartz, M. F., Martin, N., Saffran, E. M., \& Gagnon, D. A. (1997). Lexical access in aphasic and nonaphasic speakers. Psychological Review, 104(4), 801-838. http://dx.doi. org/10.1037/0033-295X.104.4.801.
Duñabeitia, J. A., Cholin, J., Corral, J., Perea, M., \& Carreiras, M. (2010). SYLLABARIUM: An online application for deriving complete statistics for Basque and Spanish orthographic syllables. Behavior Research Methods, 42(1), 118-125. http:// dx.doi.org/10.3758/BRM.42.1.118.

Fox, J., \& Weisberg, S. (2011). An $\{R\}$ Companion to Applied Regression (2nd ed.). Thousand Oaks, CA: Sage.

Garrett, M. (1980). Levels of processing in sentence production. In B. Butterworth (Ed.), Language production Vol. 1: Speech and talk (pp. 177-220).

Goldrick, M., \& Blumstein, S. E. (2006). Cascading activation from phonological planning to articulatory processes: Evidence from tongue twisters. Language and Cognitive Processes, 21, 649683. http://dx.doi.org/10.1080/01690960500181332.

Goldrick, M., Folk, J. R., \& Rapp, B. (2010). Mrs. Malaprop's neighborhood: Using word errors to reveal neighborhood structure. Journal of Memory and Language, 62, 113-134. http:// dx.doi.org/10.1016/j.jml.2009.11.008

Gordon, J. K. (2002). Phonological neighborhood effects in aphasic speech errors: Spontaneous and structured contexts. Brain and Language, 82,113-145. http://dx.doi.org/10.1016/ S0093-934X(02)00001-9.

Gordon, J. K., \& Dell, G. (2001). Phonological neighborhood effects: Evidence from aphasia and connectionist modeling. Brain and Language, 79, 21-23.

Jescheniak, J. D., \& Levelt, W. (1994). Word frequency effects in speech production: Retrieval of syntactic information and of phonological form. Journal of Experimental Psychology: Learning, Memory, and Cognition, 20(4), 824-843. http:// dx.doi.org/10.1037/0278-7393.20.4.824.

Kent, R. D., Kent, J. F., \& Weismer, G. (2000). What dysarthrias can tell us about the neural control of speech. Journal of Phonetics, 28, 273-302. http://dx.doi.org/10.1006/jpho.2000.0122.

Kent, R. D., \& Rosenbek, J. C. (1983). Acoustic patterns of apraxia of speech. Journal of Speech and Hearing Research, 26(2), 231-49. http://dx.doi.org/10.1044/jshr.2602.231.

Kurowski, K., \& Blumstein, S. E. (2016). Phonetic basis of phonemic paraphasias in aphasia: Evidence for cascading activation. Cortex, 75, 193-203. http://dx.doi.org/10.1016/j.cortex.2015.12.005.

Laganaro, M. (2015). Paraphasies phonémique et/ou phonétiques? Des raisons et des difficultés de cette distinction. Revue de Neuropsychologie, 7, 27-32. http://dx.doi.org/10.3917/rne.071.0027.

Laganaro, M., \& Alario, F. X. (2006). On the locus of syllable frequency effect. Journal of Memory and Language, 55, 178-196. http://dx.doi.org/10.1016/j.jml.2006.05.001.

Laganaro, M., \& Zimmermann, C. (2010). Origin of phoneme substitution and phoneme movement errors in aphasia. Language Cognitive Processes, 25, 1-37. http://dx.doi.org/10.1080/01690960902719259.

Lecours, A. R., \& Lhermitte, F. (1969). Phonemic paraphasias: Linguistic structures and tentative hypotheses. Cortex, 5, 193-228. http://dx.doi.org/10.1016/S0010-9452(69)80031-6.

Levelt, W. (1989). Speaking: From intention to articulation. Cambridge, MA: MIT Press.

Levelt, W. (1999). Models of word production. Trends in Cognitive Sciences, 3(6), 223-232. http://dx.doi.org/10.1016/ S1364-6613(99)01319-4.

Levelt, W., \& Wheeldon, L. R. (1994). Do speakers have access to a mental syllabary? Cognition, 50, 239-269. http://dx.doi. org/10.1016/0010-0277(94)90030-2.

Lüdecke, D. (2015). sjPlot: Data Visualization for Statistics in Social Science [software package]. Retrieved from https://mran. microsoft.com/package/sjPlot/.

Marian, V., Bartolotti, J., Chabal, S., \& Shook, A. (2012), CLEARPOND: Cross-Linguistic Easy-Access Resource for Phonological and Orthographic Neighborhood Densities. PLOS ONE, 7(8), e43230. http://dx.doi.org/10.1371/journal.pone.0043230.

Nespoulous, J.-L., Baqué, L., Rosas, A., Marczyk, A., \& Estrada, M. (2013). Aphasia, phonological and phonetic voicing within the consonantal system: Preservation of phonological oppositions and compensatory strategies. Language Sciences, 39, 117-125. http://dx.doi.org/10.1016/j.langsci.2013.02.015. 
Nespoulous, J.-L., Joanette, Y., Ska, B., Caplan, J. D., \& Lecours, A. R. (1987). Production deficits in Broca's and conduction aphasia: Repetition versus reading. In E. Keller \& M. Gopnik (Eds.), Motor and sensory processes of language (pp. 53-81). Hillsdale, NJ: Lawrence Erlbaum.

Nespoulous, J.-L., Lecours, A. R., \& Joanette, Y. (1983). La dichotomie phonétique/phonologique a-t-elle une valeur nosologique? In P. Messerli, P. M. Lavorel \& J.-L. Nespoulous (Eds.), Neuropsychologie de l'expression orale (pp. 71-91). Paris: Editions du C.N.R.S

Nickels, L., \& Howard, D. (1999). Effects of lexical stress on aphasic word production. Clinical Linguistics and Phonetics, 13, 269-294. http://dx.doi.org/10.1080/026992099299086.

Plaut, D. C. (1995). Double dissociation without modularity: Evidence from connectionist neuropsychology. Journal of Clinical and Experimental Neuropsychology, 17(2), 291-321. http:// dx.doi.org/10.1080/01688639508405124.

Pouplier, M., \& Hardcastle, J. W. (2005). A re-evaluation of the nature of speech errors in normal and disordered speakers. Phonetica, 62, 227-243. http://dx.doi.org/10.1159/000090100.

Pouplier, M., Marin, S., \& Waltl, S. (2014). Voice onset time in consonant cluster errors: Can phonetic accommodation differentiate cognitive from motor errors? Journal of Speech, Language, and Hearing Research, 57, 1577-1588. http://dx.doi. org/10.1044/2014 JSLHR-S-12-0412.

R Development Core Team. (2011). R: A Language and Environment for Statistical Computing. Vienna, Austria. Retrieved from http://www.r-project.org.

Rapp, B., \& Goldrick, M. (2000). Discreteness and interactivity in spoken word production. Psychological Review, 107(3), 460 499. http://dx.doi.org/10.1037/0033-295X.107.3.460.

Romani, C., Olson, A., Semenza, C., \& Granà, A. (2002). Patterns of phonological errors as a function of a phonological versus an articulatory locus of impairment. Cortex, 38(4), 541-567. http://dx.doi.org/10.1016/S0010-9452(08)70022-4.

RStudio Team (2015). RStudio: Integrated Development Environment for R. Boston, MA: RStudio, Inc.

Ryalls, J. (1986). An acoustic study of vowel production in aphasia. Brain and Language, 29, 48-67. http://dx.doi. org/10.1016/0093-934X(86)90033-7.
Shallice, T. (1988). From neuropsychology to mental structure. Cambridge, UK: Cambridge University Press. http://dx.doi. org/10.1017/CBO9780511526817.

Tesak, J., \& Code, C. (2008). Milestones in the history of aphasia: Theories and protagonists. London: Psychology Press.

Thomas, M. S. C., \& McClelland, J. L. (2008). Connectionist models of cognition. In R. Sun (Ed.), Cambridge handbook of computational psychology (pp. 23-58). Cambridge, UK: Cambridge University Press. http://dx.doi.org/10.1017/CBO9780511816772.005.

Tuller, B., \& Seider Story, R. (1988). Anticipatory and carryover coarticulation in aphasia: An acoustic study. Cognitive Neuropsychology, 5(6), 747-771. http://dx.doi.org/10.1080/02643298808253281.

Valdois, S., \& Nespoulous, J.-L. (1998). Perturbation du traitement phonologique et phonétique du langage. In X. Séron \& M. Jeannerod (Eds.), Traité de Neuropsychologie Humaine (pp. 360-374). Liège: Mardaga.

Varley, R. A., \& Whiteside, S. P. (1998). A reconceptualisation of apraxia of speech: A synthesis of evidence. Cortex, 34, 221231. http://dx.doi.org/10.1016/S0010-9452(08)70749-4.

Varley, R. A., \& Whiteside, S. P. (2001). What is the underlying impairment in acquired apraxia of speech. Aphasiology, 15, 39-49.

Vijayan, A., \& Gandour, J. (1995). On the notion of a "subtle phonetic deficit" in fluent/posterior aphasia. Brain and Language, 48(2), 106-119. http://dx.doi.org/10.1006/brln.1995.1004.

Vitevitch, M. S. (1997). The neighborhood characteristics of malapropisms. Language and Speech, 40(3), 211-228. http://dx.doi. org/10.1121/1.415242.

Vitevitch, M. S. (2002). The influence of phonological similarity neighborhoods on speech production. Journal of Experimental Psychology: Learning, Memory, and Cognition, 28(4), 735747. http://dx.doi.org/10.1037/0278-7393.28.4.735.

Vitevitch, M. S., \& Stamer, M. K. (2006). The curious case of competition in Spanish speech production. Language and Cognitive Processes, 21, 760-770. http://dx.doi.org/10.1080/01690960500287196.

Ziegler, W. (2002). Psycholinguistic and motor theories of apraxia of speech. Seminars in Speech and Language, 23, 231-243. http://dx.doi.org/10.1055/s-2002-35798.

Ziegler, W. (2008). Neurophonetics. In M. J. Ball, N. Müller, M. R. Perkins \& S. Howard (Eds.), Handbook of Clinical Linguistics. Oxford: Blackwell. http://dx.doi.org/10.1002/9781444301007.ch31.

\section{APPENDIX}

Table 1. Linguistic description of patients.

\begin{tabular}{|c|c|c|c|c|c|c|c|}
\hline Patient & Age & $\begin{array}{c}\text { Aphasia } \\
\text { type }\end{array}$ & $\begin{array}{c}\text { Native } \\
\text { tongue }\end{array}$ & $\begin{array}{c}\text { Permanent residence } \\
(>\mathbf{1 0} \text { years })\end{array}$ & $\begin{array}{c}\text { Permanent residence } \\
(>\mathbf{1 0} \text { years) }\end{array}$ & $\begin{array}{c}\text { Bilingual } \\
\text { (catalan) }\end{array}$ & $\begin{array}{c}\text { Other } \\
\text { languages }\end{array}$ \\
\hline FNG & 68 & B & Spanish & Barcelona & NA & yes & Italian \\
\hline FRG & 61 & B & Spanish & Barcelona & Alicante & no & NA \\
\hline MFB & 45 & B & Spanish & Barcelona & NA & yes & English \\
\hline JLLV & 40 & B & Catalan & Barcelona & NA & yes & English \\
\hline CPB & 48 & C & Spanish & Barcelona & NA & yes & NA \\
\hline LFC & 57 & C & Spanish & Barcelona & NA & no & NA \\
\hline JMC & 50 & C & Spanish & Barcelona & NA & no & English \\
\hline JAOF & 57 & C & Spanish & Barcelona & NA & yes & NA \\
\hline
\end{tabular}


Predicting segmental substitution errors in aphasic patients with phonological and phonetic encoding impairments $\bullet 15$

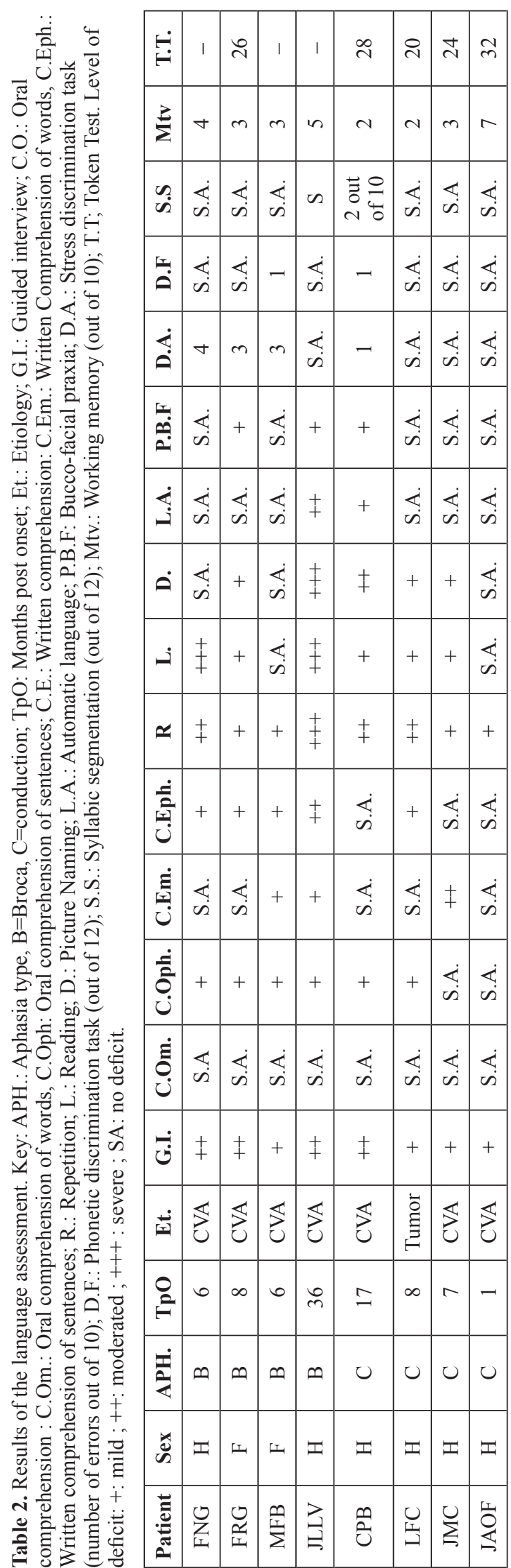

